\title{
A SEMIÓTICA APLICADA À PUBLICIDADE: UM ESTUDO SOBRE DIFERENTES ANÚNCIOS IMPRESSOS DA MARCA DE COSMÉTICOS SEDA
}

\author{
Semiotics Applied to Advertising: A Study of Different Forms of Advertising's \\ Cosmetics Seda
}

\section{Semiótica Aplicada à la Publicidad: un estudio sobre los diferentes anuncios de la marca de cosméticos Seda}

\author{
Raquel Marques Carriço Ferreira ${ }^{1}$ \\ Dhione Oliveira Santana ${ }^{2}$
}

\begin{abstract}
Resumo
O presente artigo pretende aplicar a análise semiótica peirciana sobre os anúncios publicitários impressos de diferentes produtos da marca "Seda". A pesquisa foi baseada no modelo didático-pedagógico proposto por Lúcia Santaella (2002), a partir dos três pontos de vista semióticos peircianos apresentados pela pesquisadora para a realização da análise. Também procedemos às revisões bibliográficas sobre a comunicação publicitária para conceituar o tema aqui tratado.
\end{abstract}

Palavras-chave semiótica, análise imagética, publicidade, anúncio impresso.

\begin{abstract}
This article seeks to apply the Peircean semiotic analysis on printed advertisements of different products of the brand "Seda". The research was based on the didactic-pedagogical model proposed by Lucia Santaella (2002), from three points of view presented by Peirce. Here, we also review the literature on advertising communication to conceptualize the subject matter presented.
\end{abstract}

Keywords: semiotics, imagetic analysis, advertising, printed ad.

\footnotetext{
${ }^{1}$ Orientadora do trabalho. Doutora em Televisão e Cinema pela Universidade Nova de Lisboa, Professora do Curso de Publicidade e Propaganda da Universidade Federal de Sergipe, UFS. E-mail: raquelcarrico@ gmail.com ${ }^{2}$ Autor do Trabalho, formando do Curso de Publicidade e Propaganda da UFS. Bolsista de Iniciação Científica do CNPq. E-mail: odhione@ gmail.com
} 
A semiótica aplicada à publicidade: um estudo sobre diferentes anúncios impressos da marca de cosméticos seda

de Dhione Oliveira Santana e Raquel Marques Carriço Ferreira

\section{Resumen}

Este artículo tiene como objetivo aplicar el análisis semiótico de Peirce de los anuncios impresos de los diferentes productos de la marca "Silk". La investigación se basó en el modelo didáctico-pedagógico propuesto por Lucia Santaella (2002), desde tres puntos de vista semiótico de Peirce presentados por el investigador para llevar a cabo el análisis. También se procedió a la revisión de la literatura sobre la comunicación publicitaria para conceptualizar el objeto del mismo.

Palabras clave: semiótica, análisis de imágenes, publicidad, anuncio impreso

\section{INTRODUÇÃO}

Muito se fala sobre os processos comunicativos que envolvem a publicidade e a semiótica $^{3}$, como de certo a ciência semiótica tem-se utilizado das mensagens publicitárias como objeto de análise ${ }^{4}$. Para Souza \& Santarelli (2006) os estudos voltados para análise da imagem nos anúncios publicitários começaram a ser desenvolvidos em 1964 com o francês Roland Barthes, que foi o primeiro investigador a tomar o anúncio impresso como objeto a ser investigado, apresentando as conotações e denotações das imagens; as funções linguísticas do texto de ancoragem e o apontamento da complementaridade de uma imagem e os aspectos da retórica visual.

Neste direcionamento, Souza \& Santarelli (2006) ainda complementam que juntamente com Barthes, Umberto Eco contribuiu para os primeiros estudos semióticos ${ }^{5}$ sobre os anúncios impressos, porém ao contrário de Barthes que via a imagem como um todo, Eco entendia que o anúncio poderia ser decomposto em unidades menores, através do registro verbal e visual (icônico), dividindo o anúncio em cinco níveis: icônico, iconográfico, tropológico, tópico e entimemático; em que os primeiros níveis tratavam dos aspectos visuais e os três restantes da argumentação.

Umberto Eco desenvolveu suas teorias sobre a interpretação dos signos tomando como uma das bases os ideais do filósofo norte-americano Charles Peirce. O pesquisador norteamericano argumenta que os signos podem ser interpretados através de três formas: "a

\footnotetext{
${ }^{3}$ De uma maneira ampla significa o estudo de todos os signos.

${ }^{4}$ Parágrafo baseado no artigo Publicidade Visual: Uma proposta de percurso analítico da imagem persuasiva (SOUZA \& SANTARELLI: 2006).

${ }^{5}$ Silogismo em que só há antecedente e consequente.
} 
A semiótica aplicada à publicidade: um estudo sobre diferentes anúncios impressos da marca de cosméticos seda

de Dhione Oliveira Santana e Raquel Marques Carriço Ferreira

dedução (prova, que algo deve ser), a indução (a indução mostra que alguma coisa é realmente operativa) e a abdução (sugere simplesmente que alguma coisa pode ser)" (PEIRCE, 1990).

De acordo com a pesquisadora Martine Joly (1996) em seu livro "Introdução à Análise das Imagens" (1994), a análise da imagem publicitária deve ter procedimento com o objetivo de verificar o desempenho desta, isto pela necessidade de justificar os gastos na veiculação das mensagens. No Brasil, a pesquisadora Lúcia SANTAELLA (2002) nos fornece um modelo didático de análise do anúncio impresso, baseado nos princípios da semiótica peirciana: - todo processo comunicativo apresenta-se em três pontos de vista: icônico, significação ou primeiridade (a expressão objetiva), indicial, referência ou secundidade (o signo pode ser tomado, em uma relação de causa e efeito, como representação de uma segunda coisa) e metafórico, convencional-simbólico ou terceiridade (expressão máxima da síntese informativa, a relação com o objeto é arbitrária, regida por uma norma social).

Com o uso deste instrumental, o objetivo deste trabalho é o de investigar os anúncios publicitários, em específico, três anúncios impressos de produtos diferentes da marca Seda. Os anúncios considerados foram escolhidos por causa do seu potencial comunicativo orientados para os interesses econômicos do anunciante.

\section{UMA EXPOSIÇÃO EXPLICATIVA DOS TRÊS NÍVEIS SEMIÓTICOS:}

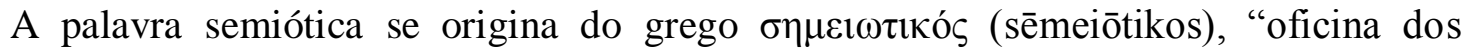
signos", ou seja, a ciência geral dos signos e dos fenômenos culturais como sistemas de significações. Tão estranho quanto a palavra semiótica, é o seu objeto de estudo em uma primeira impressão: "signo". Grosso modo, signo tem o mesmo significado de linguagem, isto é, algo que significa alguma coisa.

Um signo intenta representar, em parte pelo menos, um objeto que é, portanto, num certo sentido, a causa ou determinante do signo, mesmo se o signo representar seu objeto falsamente. Mas dizer que ele representa seu objeto implica que ele afete uma mente, de tal modo que, de certa maneira, determine naquela mente algo que é imediatamente devido ao objeto. Essa determinação da qual a causa mediata ou determinante é o signo, e da qual causa mediata é o objeto, pode ser chamada o Interpretante. (SANTAELLA 1990: 78)

Na visão de Lúcia Santaella (1996) a semiótica é a ciência que tem a missão de investigar todos os signos ou linguagens, permitindo assim, compreender palavras, imagens, 
A semiótica aplicada à publicidade: um estudo sobre diferentes anúncios impressos da marca de cosméticos seda

de Dhione Oliveira Santana e Raquel Marques Carriço Ferreira

sons em todas as dimensões possíveis, através de esquemas perceptivos, alicerçado através de três categorias fenomenológicas capazes de compreender tudo que é, pode ser, ou será, ou seja, o significado, referente e o significante das coisas.

Título - Três Níveis Possíveis de Compreensão dos Signos

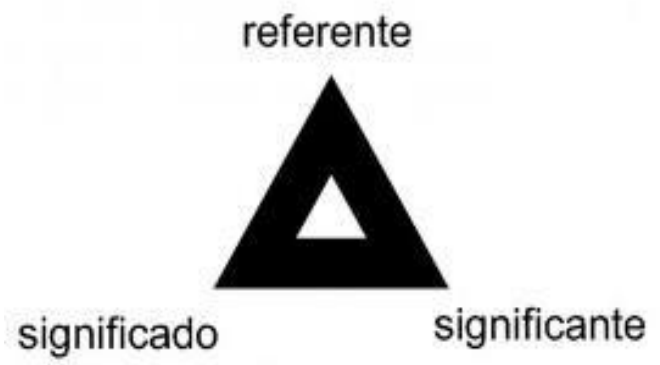

Sob o ponto de vista do significado, segundo a semiótica peirciana e de acordo com SANTAELLA (2002), é tudo aquilo que surge na mente do receptor na primeira olhada, que explora as qualidades sensoriais das propriedades internas de uma mensagem visual, por exemplo, com sua linguagem, cores, linhas, formas, volume, luz, movimento. Tais aspectos são responsáveis pela impressão mais pura que uma imagem provoca no receptor. Portanto, segundo Gomes (2000), na primeiridade, o signo é visto de maneira singular, puro, sem existir.

Sob o ponto de vista do referente, o aspecto- em que o produto está inserido, os traços da sua identidade, as finalidades a que se presta e a adequação qualitativo-icônico são analisados, mantendo assim, uma conexão física com o objeto representado, por exemplo, a predominância de cores quentes, principalmente dos tons de amarelo/vermelho em um anúncio funciona como índice que ele se refere ao um produto típico do verão. Por fim, “o índice, como seu próprio nome diz, é um signo que como tal funciona porque indica uma outra coisa como a qual ele está factualmente ligado" (SANTAELLA, 1996: 90).

Segundo Cândido, Valentim \& Contani (2005) sob o ponto de vista do significante o signo apresenta associado às ideias gerais, o que faz com que ele seja interpretado como se referindo àquele objeto, extraindo o poder de representação que foi convencionado de forma arbitrária, exemplo, as cores verde e amarelo que simbolizam a nação brasileira (cores da bandeira nacional). Santaella (2002) aponta que neste nível semiótico o anúncio é analisado 
A semiótica aplicada à publicidade: um estudo sobre diferentes anúncios impressos da marca de cosméticos seda

de Dhione Oliveira Santana e Raquel Marques Carriço Ferreira

como algo que existe articulado em um determinado tempo e espaço, ou seja, existe um contexto cultural que permite dar significação ao objeto.

Por fim, existe uma inter-relação entre os três níveis semióticos propostos por Peirce. Segundo Gomes (2000) a primeiridade está ligada a percepção imediata não possibilitando assim o estabelecimento de diferenciações. A partir da percepção imediata nossos sentidos buscam direcionar e intensificar a comunicação em uma ação interativa que inaugura o processo de diferenciação, posteriormente, com base no nosso conhecimento e nas representações de mundo se intensifica ainda mais nossas percepção partindo assim para o terceiro estágio o do significante, que corresponde aos nossos conhecimentos adquiridos. Exemplo, nuvens escuras no céu, em um primeiro momento pode ser interpretado como simples nuvens, em um segundo momento torna-se sinal de chuva e um terceiro momento pode significar fatura e colheita para milhares de sertanejos. Tal como posto, esta é a relação de interdependência estabelecida.

A seguir demonstraremos a aplicabilidade da semiótica peirciana em três anúncios impressos da marca de cosméticos "Seda". Os anúncios selecionados foram os três últimos anúncios impressos presentes no site da empresa Unilever detentora da marca Seda.

\section{APLICANDO A TEORIA AOS ANÚNCIOS SELECIONADOS:}

A primeira peça a ser analisada foi veiculada em 2002, para divulgar pela segunda vez a linha de produtos "Seda Verão Intenso", composta por Xampu, condicionador, máscara e leave-in ${ }^{6}$. Segundo a empresa UNILEVER (2012) os produtos desta linha possuem ativos para proteger os cabelos contra os danos do verão, recuperando a hidratação e flexibilidade perdidas em função das agressões do sol, da água e do vento.

Agora depois de uma rápida exposição sobre a peça cabe a nós analisá-la aplicando a proposta da semiótica peirciana:

\footnotetext{
${ }^{6}$ Creme para ser usado nos cabelos, logo após a lavagem com xampu e o condicionador.
} 


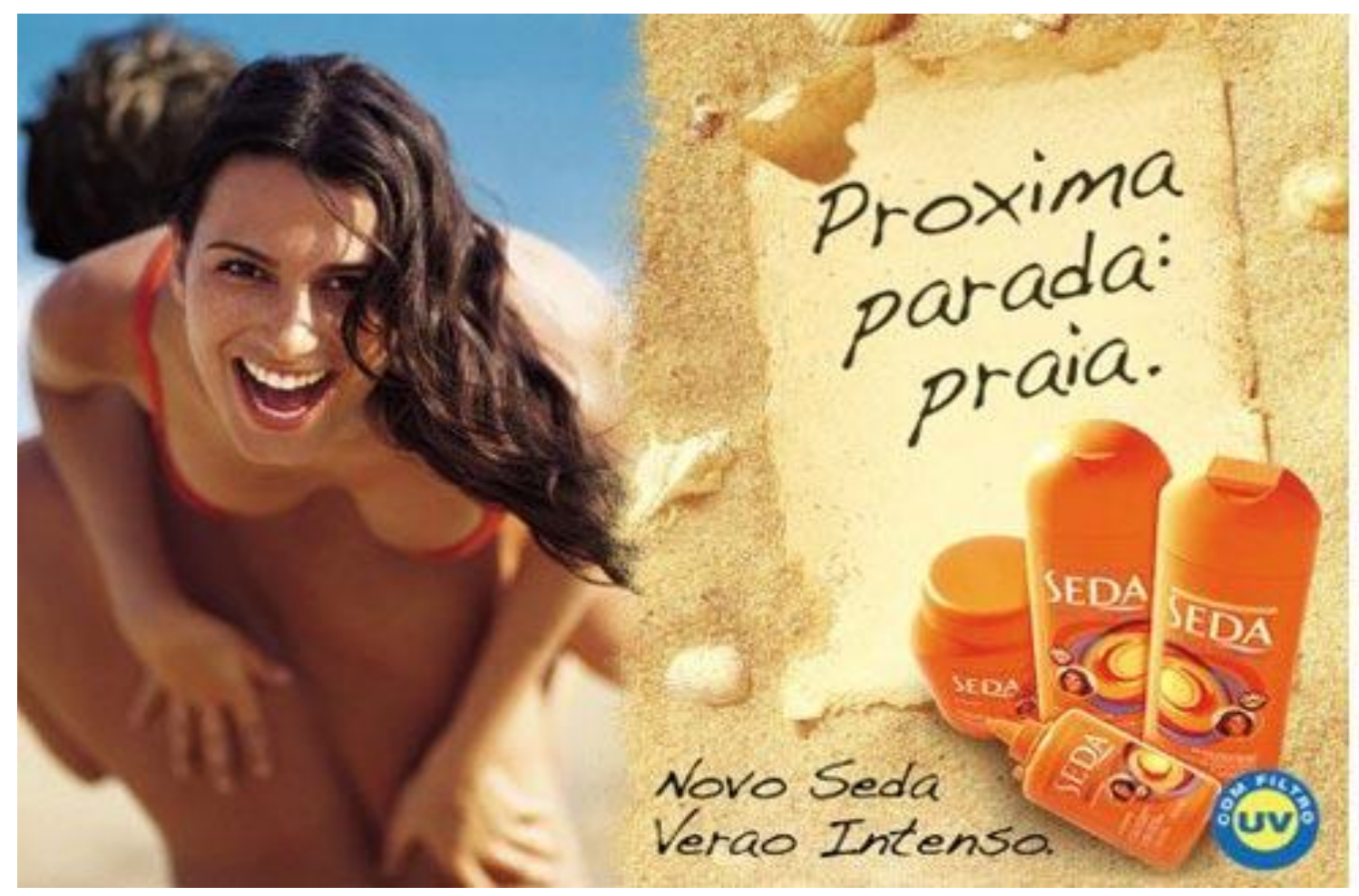

Em um primeiro momento sob o ponto de vista da primeiridade, vemos que o anúncio se apresenta dividido em duas imagens. Do lado esquerdo vemos uma mulher sendo carregada nos ombros por um homem, percebemos também que o homem está sem camisa e a mulher com biquíni, destaca-se no fundo superior da imagem o céu azulado. Do lado direito vemos areia, pedras brancas, os produtos seda da Linha Seda Verão Intenso, um papel que se assemelha ao um papiro com a seguinte frase: Próxima parada: praia destaca-se por fim, o nome "Novo Seda Verão Intenso" na parte inferior e o logo que diz "Com Filtro UV".

Se aguçarmos nosso olhar em um segundo nível, o do referente, percebemos que todo anúncio exalta o contexto do uso do produto anunciado, o ambiente de verão com praia, areia, conchas, todas as imagens alusivas ao ambiente próprio do brasileiro no período do verão, a figura da mulher e do homem em trajes típicos de praia em alusão a momentos de diversão neste contexto. O texto, as cores estão se referindo aos produtos "Seda Verão Intenso", o logotipo do "filtro UV" ressalta ainda mais as qualidades da linha de produtos. Em síntese vêse que em todo o anúncio predomina as cores fortes, principalmente, a luminosidade típica do verão.

Em um terceiro nível o da terceiridade, o anúncio transmite a ideia geral de com o "Seda Verão Intenso", a consumidora pode se divertir tranquilamente na praia pois os cabelos 
A semiótica aplicada à publicidade: um estudo sobre diferentes anúncios impressos da marca de cosméticos seda

de Dhione Oliveira Santana e Raquel Marques Carriço Ferreira

ficarão com o produto hidratados e protegidos, mais especificamente, com um protetor solar contido no produto e que livra os cabelos das agressões e danos causados pelo sol.

\section{Segundo Anúncio - Seda Lissage:}

A segunda peça a ser analisada também foi veiculada em 2002, para divulgar a linha de produtos Seda Lissage especializada em cuidados com os cabelos lisos. Os produtos foram desenvolvidos depois de que uma pesquisa revelou que $87 \%$ das mulheres queriam que seus cabelos fossem mais lisos. Os produtos criados para a linha foram: Xampu, Condicionador, Creme para Pentear e Creme de tratamento.

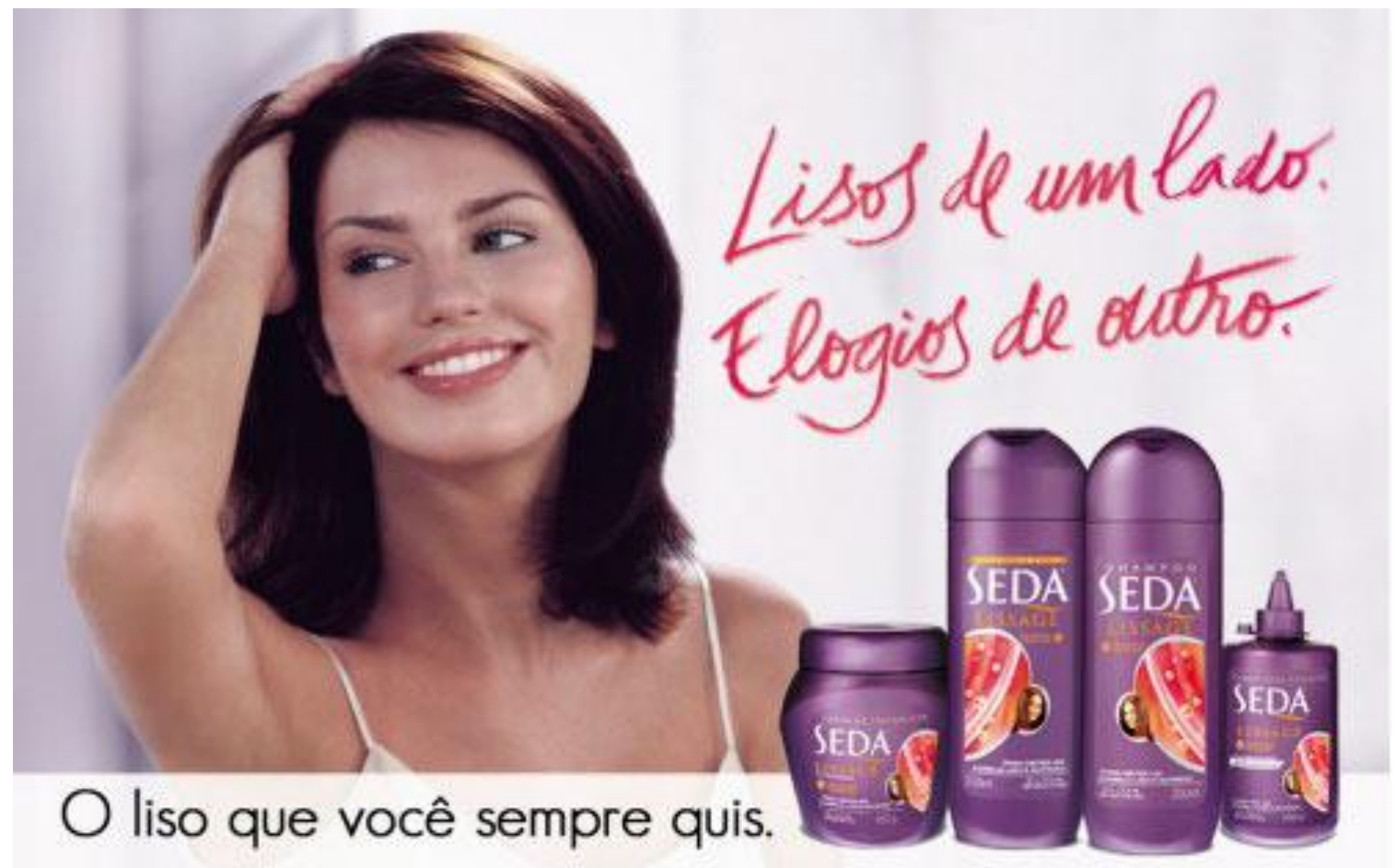

Analisando o anúncio em questão, no ponto de vista da primeiridade, vê-se,uma mulher com a mão no cabelo, os produtos da Linha Seda Lissage em um primeiro plano, no fundo uma cortina de seda, as cores que predominam são frias, e a frase "Liso de um lado. Elogios de outros" e o slogan "O liso que você sempre quis" aparecem de forma destacada.

Em um segundo nível, o do referente, percebemos que todo o contexto do anúncio traz a sensação de leveza, pureza e os relacionada com o produto anunciado. Os lisos dos cabelos, do plano de fundo reforçam as qualidades da linha de produtos que está no primeiro plano, as letras da frase "Lisos de um lado. Elogios de outro", faz uma comparação expressa entre a 
A semiótica aplicada à publicidade: um estudo sobre diferentes anúncios impressos da marca de cosméticos seda

de Dhione Oliveira Santana e Raquel Marques Carriço Ferreira

imagem feminina e os produtos, além é claro, das cores frias que reforçam o destaque do produto que é percebido em cor contrastante do roxo.

No terceiro nível, o do significante, podemos perceber que o anúncio transmite a mensagem geral que com os produtos Seda Lissage a consumidora pode ter o "tão sonhado" cabelo liso e se tornar assim uma mulher verdadeiramente realizada.

\section{Terceiro Anúncio - Seda Anti Sponce:}

O anúncio ser analisado a seguir foi veiculado em 2006, com o objetivo de divulgar a linha de produtos Seda Anti-Sponge, voltados para cabelos armados e com frizz (rebeldes e eletrizados), composta por xampu, condicionador e leave-in.

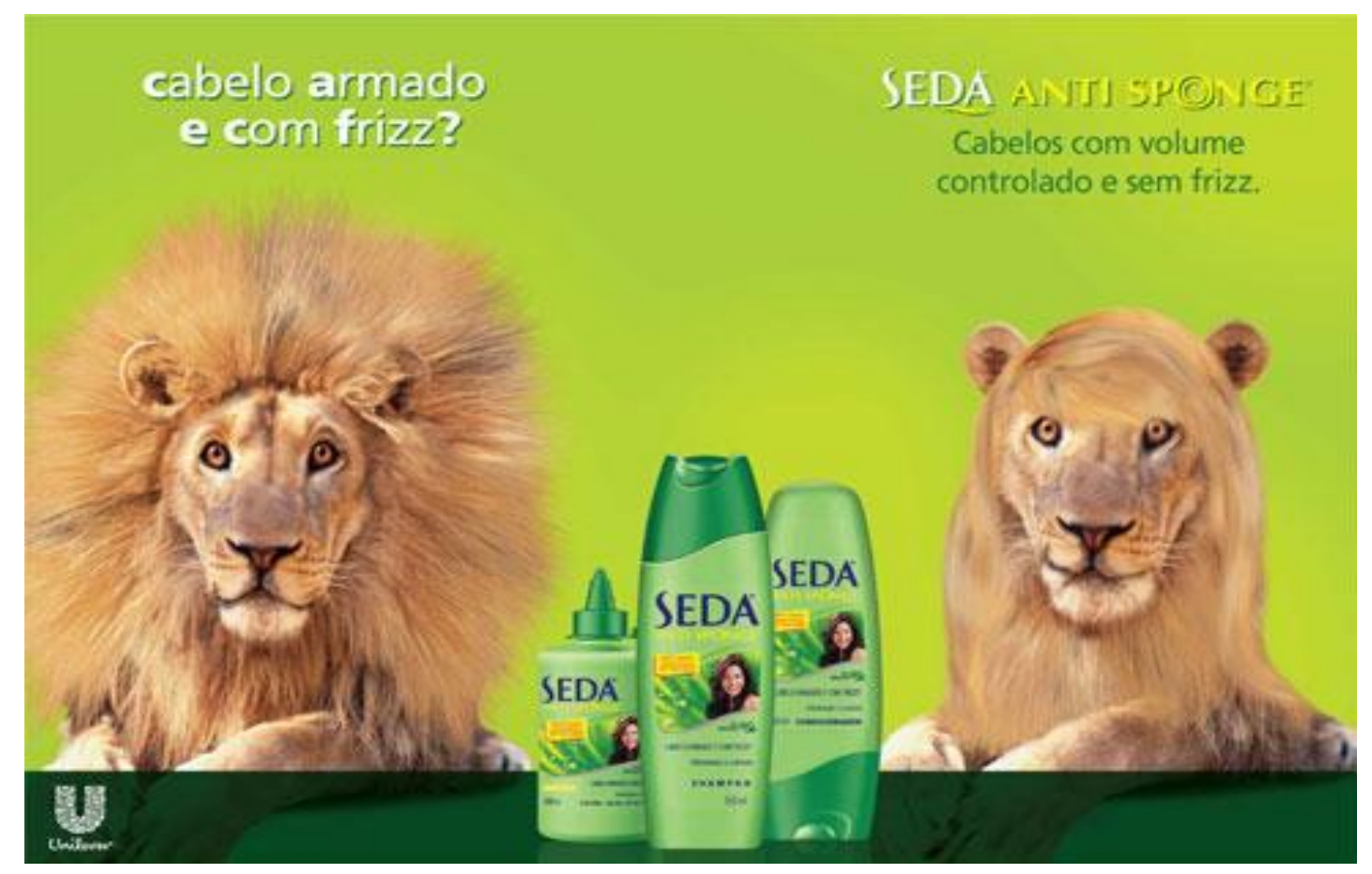

Do ponto de vista do significado, um anúncio apresenta dois leões, um do lado esquerdo e outro do lado direito e no centro os produtos da linha Anti Spone, verifica-se também um plano de fundo verde, e os seguintes textos: “Cabelo Armado com Frizz?” Em cima do leão da esquerda e Seda Anti Spone, vê-se: "Cabelos com volume controlado e sem frizz". A imagem portanto, nos fornece uma primeira impressão singular.

Do ponto de vista do referente, todo o anúncio está ligado à linha de produtos anunciados que inclusive se encontram em primeiro plano. O verde no plano de fundo e na 
A semiótica aplicada à publicidade: um estudo sobre diferentes anúncios impressos da marca de cosméticos seda

de Dhione Oliveira Santana e Raquel Marques Carriço Ferreira

faixa da frente funciona como referente da cor dos produtos, a forma como o cabelo dos referencia os benefícios dos produtos, o próprio texto está posicionado de maneira estratégica para referencia com o uso dos produtos.

Do ponto de vista do significante, simbolicamente vê-se que o anunciante trocou a imagem de uma mulher pela a de um leão, que por analogia metafórica é bastante utilizado como referencia entre as mulheres que "têm uma juba de leão", ou seja, um cabelo volumoso como o da juba de leão. As consumidoras devem deduzir que se esta linha de produtos foi capaz de alisar até a juba do leão, com certeza será capaz de controlar o volume dos seus cabelos.

\section{CONSIDERAÇÕES FINAIS:}

A aplicabilidade da semiótica em anúncios são constantes Roland Barthes foi o pioneiro, porém não são poucos, os autores que tem investigado a comunicação sobre diferentes óticas. Charles Peirce (1839-1919), apesar de nunca ter investigado os anúncios publicitários, fornece com seus ideais, a base da análise aqui adotada. Lúcia Santaella (2002) resgata os princípios defendidos pela semiótica peirciana e os aplica ao potencial comunicativo da publicidade.

Depois se analisar semioticamente os anúncios impressos da marca Seda, verificou-se que os três pontos de vista peircianos (ponto de vista do significado, expressão objetiva do signo; ponto de vista do referente, signo pode ser tomado, em uma relação de causa e efeito; ponto de vista do significante, expressão máxima da síntese informativa) são propostas eficientes na análise da eficácia das mensagens publicitárias e permitem visualizar de forma simples a construção dos anúncios publicitários.

Em síntese, os anúncios analisados seguiram a tendência de simplificar a apresentação dos produtos, toda a composição imagética faz analogia ao contexto de uso ou categoria funcional do produto. A simplicidade dos argumentos também são elementos que compuseram tal tendência: contexto de uso, qualidades funcionais dos produtos, consequências sociais para o individuo que se beneficiam do produto foram os argumentos primários da mensagem publicitária e que, embora "batidos", são eficientes para a promoção de produtos e serviços. 
A semiótica aplicada à publicidade: um estudo sobre diferentes anúncios impressos da marca de cosméticos seda

de Dhione Oliveira Santana e Raquel Marques Carriço Ferreira

\section{REFERÊNCIAS BIBLIOGRÁFICAS}

BARTHES, R. “A retórica da imagem”, In: O óbvio e o obtuso. Rio de Janeiro: Nova Fronteira, 1990.

BRAGA, M. L. S.. As três categorias peircianas e os três registros lacanianos. Psicol. USP [online]. 1999, vol.10, n.2: 81-91. ISSN 0103-6564. http://dx.doi.org/10.1590/S010365641999000200006.

CÂNDIDO, C. A; VALENTIM, M. L; CONTANI, M. L. Gestão estratégica da informação: A semiótica aplicada ao processo de tomada de decisão. DataGramaZero: Revista de Ciência da Informação, Rio de Janeiro, v. 6, n. 3, jun. 2005. Disponível em: <http://www.dgz.org.br/jun05/F_I_art.htm>. Acesso em: 22 jun. 2012.

CHARAUDEAU, P. Discurso das mídias. São Paulo: Contexto, 2006.

DONDIS, D. A. Sintaxe da linguagem visual. 2. Ed. São Paulo: Martins Fontes, 1997.

FARINA, M.. Psicodinâmica das cores em comunicação. 2ł. ed. São Paulo: Edgard Blücher, 1986.

GOMES, M. C. A.. Ação social midiatizada: analisando a recontextualização de um evento social. Ling. (dis)curso (Impr.), Tubarão, v. 10, n. 2, Aug. 2010 . Available from $<$ http://www.scielo.br/scielo.php?script=sci_arttext\&pid=S1518-

$76322010000200004 \& \operatorname{lng}=\mathrm{en} \& \mathrm{nrm}=\mathrm{iso}>$. access on 10 June 2012. http://dx.doi.org/10.1590/S1518-76322010000200004.

JOLY, M.. Introdução à análise da imagem. Campinas: Papirus, 1996: 152

KOTLER, P. Administração de marketing. [10. ed.] São Paulo, SP: Prentice Hall, 2000. P. ; KELlER, KEVIN; L.. Administração de marketing. 12. ed. São Paulo: Pearson, 2006.

P.,; ARMSTRONG, G. Princípios de marketing. 12. ed. Rio de Janeiro: Livros Técnicos e Científicos, 2009.

GOMES, Henriette Ferreira. O ambiente informacional e suas tecnologias na construção dos sentidos e signifi cados. Ciência da Informação, Brasília, v. 29, n. 1: 61-70, jan./abr. 2000.

MAGALHAES, I. Critical discourse analysis and the semiotic construction of gender identities. DELTA, São Paulo, v. 21, n. spe, 2005 . Available from $<$ http://www.scielo.br/scielo.php?script=sci_arttext\&pid=S0102- 
A semiótica aplicada à publicidade: um estudo sobre diferentes anúncios impressos da marca de cosméticos seda

de Dhione Oliveira Santana e Raquel Marques Carriço Ferreira

44502005000300011\&lng=en\&nrm=iso>. access on 10 June 2012. http://dx.doi.org/10.1590/S0102-44502005000300011.

OLIVEIRA SANTANA, D.; FERREIRA, R. Branding 360 em Telenovela. Anagrama: Revista Científica Interdisciplinar da Graduação, Brasil, v. 5, n. 3, 2012. Disponivel em http://revistas.univerciencia.org/index.php/anagrama/article/view/7907/7363. Acessado em 09 jun. 2012.

PEIRCE, Ch. S. Semiótica. Trad: J. Teixeira Coelho Netto, Perspectiva, São Paulo, 1990. Ch. S. Semiótica São Paulo Perspectiva, 2003.

SANTAELLA, L. A assinatura das coisas. Rio de Janeiro: Imago, 1992.

, L; NÖTH, W. Imagem: cognição, semiótica, mídia. 4. ed. São Paulo, SP: Iluminuras, 2005.

,.L. O que é semiótica?São Paulo: Brasiliense, 1990.

, L. O que é semiótica? São Paulo: Brasiliense, 1996.

, L. Semiótica Aplicada. São Paulo: Thomsom Learning, 2002.

SEDA, Xampu. Disponível em:< http://pt.wikipedia.org/wiki/Seda_\%28xampu\%29> . Acesso em 22 de junho de 2012.

SEDA. Cabelos mais saudáveis para mulheres mais felizes. Disponível em: http://www.unilever.com.br/Images/Seda_tcm95-107549.pdf. Acesso em 22 de junho de 2012.

SEDA, Marca. Disponível em: http://www.unilever.com.br/brands/personalcare/seda.aspx. Acesso em 22 de junho de 2012.

SOUZA, S. SANTARELLI, C. Publicidade visual: uma proposta de percurso analítico da imagem persuasiva. Revista Galáxia, São Paulo, n. 12: 83-101, dez. 2006.

Artigo submetido: 31/05/2013

Artigo aprovado: 20/09/2013 